\title{
The impact of allergic rhinitis on work productivity [Prim Care Resp J 2007; 16(2): 98-105]
}

\section{Sheryl L Szeinbach, Enrique C Seoane-Vazquez, Andrew Beyer, P Brock Williams}

\section{See Editorial by Levy and Marshall on page 203}

In our article entitled 'The impact of allergic rhinitis on work productivity'1 which was published in this year's April issue of the Primary Care Respiratory Journal (PCRJ), we were remiss in not acknowledging the use of the same data source, data collection and background literature that was used in our previous study addressing a different issue relating to lifestyle productivity which was published in the Annals of Allergy, Asthma \& Immunology (AAAI) in 2005. ${ }^{2}$ We were also remiss in not referencing the previously published AAAI paper in the manuscript which we submitted to the PCRJ.

\section{References}

1. Szeinbach SL, Seoane-Vazquez EC, Beyer A, Williams PB. The impact of allergic rhinitis on work productivity. Prim Care Resp J 2007;16(2):98-105. doi:10.3132/pcrj.2007.00015

2. Szeinbach SL, Williams PB, Kucukarslan S, Elhefni H. Influence of patient care provider on patient health outcomes in allergic rhinitis. Ann of Allergy, Asthma and Immunol 2005;95(2):167-74.

*Sheryl L Szeinbach

Professor, Division of Pharmacy, Practice and Administration, Ohio State University, College of Pharmacy, 500 W. 12th Ave, Columbus, OH 43210-1291, USA

*Correspondence: Tel: 614-688-4249

E-mail: Szeinbach.1@osu.edu

DOI of original article; 10.3132/pcrj.2007.00015 